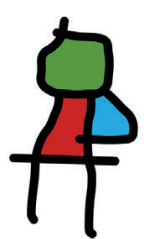

SEICAIP

\section{Allergologia et \\ immunopathologia}

Sociedad Española de Inmunología Clínica, Alergología y Asma Pediátrica

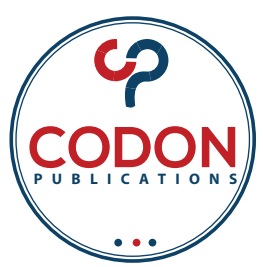

REVIEW

OPEN ACCESS (c)(1) (2)

\title{
Group 2 innate lymphoid cells (ILC2s): The spotlight in asthma pathogenesis and lung tissue injury
}

\author{
Sunusi Sadik, Yanhong Lu*, Shaoxuan Zhu, Jiayu Cai, Lan Lan Mi
}

Department of Pediatrics, Affiliated Hospital of Jiangsu University, Zhenjiang, China

Received 12 May 2020; Accepted 22 August 2020

Available online 1 March 2021

\author{
KEYWORDS \\ asthma; \\ cytokines; \\ ILC2; \\ innate lymphoid \\ cells; \\ type 2 inflammation
}

\begin{abstract}
Asthma is a heterogeneous disease with ranging etiology and severity. Asthma is a disease of chronic inflammation of the airways, with clinical symptoms of wheezing, breathlessness, cough, and chest tightness manifested as chronic fixed or variable airflow obstruction and airway hyperresponsiveness that predispose the airway epithelium to repeated injury, repair, and regeneration. In recent years, innate lymphoid cells (ILC1, ILC2, and ILC3) have been discovered. The predominant ILC type found in the lung tissue is group 2 innate lymphoid cells (ILC2s). Upon damage to the airway epithelium mediating the release of epithelial cytokines (TSLP, IL-33, and IL-25) ensued the activation of ILC2 in an antigen-independent manner. Activated ILC2 produces a significant amount of type 2 cytokines (IL-4, IL-5, IL-9, and IL-13), altogether contributing to type 2 inflammation in the airways. ILC2s are mediators of type 2 immunity for many type 2 inflammatory diseases such as asthma, since ILC2s were reported to play an important role in asthma pathogenesis. Here we discuss the role of ILC2 in the development of asthma and ILC2 effector cytokines (IL-4, IL-5, and IL-13) contributing to airway epithelial structural changes.

(c) 2021 Codon Publications. Published by Codon Publications.
\end{abstract}

*Corresponding author: Yanhong Lu, Department of Pediatrics, Affiliated Hospital of Jiangsu University, Zhenjiang, China. Email address: ihy5154@163.com 


\section{Introduction}

Asthma is a chronic clinical condition characterized by episodic symptoms of airflow obstruction, bronchial hyperresponsiveness, and airway inflammation. Asthma is the most prevalent respiratory airway disease worldwide, affecting $>300$ million people of all ethnicity, 1,2 and is the most common chronic disease in children. ${ }^{3}$ Familial history of atopic disease, genetics, environmental factors (pollutants, microbes, and exposure to passive smoking), ${ }^{4}$ and allergens, such as house dustmite allergens, ${ }^{5}$ cockroaches, ${ }^{6-8}$ pets (especially cat dander), ${ }^{9,10}$ and fungi Alternaria, ${ }^{11,12}$ are significant inducers of an asthma attack. Asthma is a phenotypically heterogeneous disease with different phenotypes. ${ }^{13}$ Asthma symptoms result from a cascade of inflammatory phase and ILC2s that release type 2-derived cytokines, which play a vital role in asthma inflammation..$^{14}$ ILC2s are a recently discovered subtype of innate lymphoid cells; they produce high amounts of type 2 cytokines, exhibit lymphoid morphology, and are non-T and non-B cells that lack antigen specificity. ${ }^{15}$ Asthma is typically regarded as a Th 2 cell-mediated disease. However, as in recent years, ILC2s have shown a critical role in the symptoms associated with asthma pathogenesis. Type 2 inflammation is the presiding mechanism underlying asthma; ${ }^{16}$ studies have shown a predominant increase of ILC2s in asthmatic patients. ${ }^{17}$ The ILC2 pathway is activated by epithelial cell-derived cytokines (IL-33, IL-25, and TSLP) upon stimulation and proceed by resulting in the production of a significant amount of its effector cytokines (IL-5, IL13, and IL-4). ${ }^{18}$ Here, in this review, we discuss our understanding of the development and activation of ILC2s and how these cells contribute to type 2 inflammation in the context of asthma.

\section{Inflammation in asthma}

Asthma is a disease of chronic inflammation that affects the lower airways, characterized by reversible airflow obstruction, airway inflammation, and airway hyperresponsiveness (AHR), with associated symptoms such as coughing, difficulty in breathing, wheezing, and chest-tightening. ${ }^{19}$ All these symptoms are mediated by immune cells such as T-lymphocytes, ${ }^{20}$ mast cells, ${ }^{21}$ neutrophils, ${ }^{22}$ eosinophils, ${ }^{23}$ epithelial cells, ${ }^{24}$ macrophages, ${ }^{25}$ NK cells, ${ }^{26}$ and ILC2s. ${ }^{27}$ Among all the pro-inflammatory mediators produced by the immune cells, the main elements are cytokines, histamines, and leukotrienes. ${ }^{28}$ In the past, clinicians classified asthma as an allergic or non-allergic disease. Nevertheless, this concept has fallen out of favor, and now it is known that asthma is a much more heterogeneous disease and differs in management and clinical severity. ${ }^{29}$ Prolonged inflammation in asthma results in swelling and inflammation of the lining of airways, thus eventually leading to structural changes in airways, ${ }^{30}$ as asthma inflammation occurs in both large (trachea) and small airways (bronchi and bronchioles). ${ }^{31}$

The airway epithelium, a defense barrier lining the airway and a major key factor in asthma pathogenesis, ${ }^{32}$ after irritation by stimulants (injury, allergens, microbes, or pollutants) tend to release a significant amount of molecules such as chemokines, cytokines, prostaglandin E2 (PGE2), endothelin, nitric oxide, and others. ${ }^{33}$ These epithelial-derived molecules cause the activation of inflammatory cells, resulting in the airways inflammation. ${ }^{34}$ Therefore, activated inflammatory cells release pro-inflammatory mediators such as cytokines, chemokines, histamines, and leukotrienes. This results in mucus hypersecretion that plugs the airways and makes it difficult to breathe, rendering vascular permeability, leading to migration of other inflammatory cells; aggravating inflammation and smooth muscle contraction; bronchial constriction; and increased bronchial permeability. ${ }^{35}$

\section{Development and survival of ILC2s}

ILC2s are the subgroup of the ILC family developed from common lymphoid progenitor (CLP) and are affiliated to the lymphoid lineage negative cells. ${ }^{36}$ ILC family (ILC1s, ILC2s, and ILC3s) is categorized based on surface markers (ILC1s: IL-7R $\alpha$, NKp44, NKp46, sca-1, and Thy-1; ILC2s: IL-7R $\alpha$, CRTH2, GATA binding protein 3 [GATA3], ST2, KLRB1, IL-17RB, and SCA-1; and ILC3s: IL-7R $\alpha$, c-kit, IL-23R, NKp44, and NKp46) (Figure 1), 37,38 transcription factors, and production of cytokines. ILCs orchestrate immune response mediated by production of cytokine (ILC1s: TNF $\gamma$; ILC2s: IL-5, IL-13, and IL-4; and ILC3s: IL-17, IL-22, and GM-CSF) (Figure 1). ILC subsets hold a close resemblance, concerning cytokine production, to the T helper subsets Th1, Th2, and Th17, respectively (Figure 1). ${ }^{39}$ Activated ILC2s by its alarmins (IL-33, IL-25, and TSLP) are released by the epithelial cells upon epithelial injury and irritation. ${ }^{40}$ ILC2s can be classified into natural ILC2 cells (nILC2) and inflammatory ILC2 cells (ilLC2). Notably, nILC2 and ilLC2 cells play different roles in the lung: ilLC2 cells mobilize to the lung from the gut to participate in rapid and transient type 2 immunity, while nILC2 cells mainly reside in the tissue and respond to viral infection. ${ }^{41}$ Also, ilLC2 cells develop significant amounts of IL-13 and small amounts of IL-5 and IL- 4 in vivo and are capable of producing large amounts of IL-13, IL-5, and IL-4 following in vitro stimulation of phorbol myristate acetate (PMA)/ionomycin. ${ }^{42}$ Furthermore, nILC2 cells express methionine enkephalin (MetEnk), ${ }^{41}$ a peptide with an immunological role in increasing numbers of cytotoxic cells against viral infection and tumor cells. Treatment with MetEnk inhibits influenza A virus $(\mathrm{H} 1 \mathrm{~N} 1)$ replication ${ }^{43}$ whether ilLC2 cells express MetEnk is to be determined. ${ }^{41}$ Similarly, nILC2 cells produce amphiregulin, which plays a vital role in maintaining the integrity of epithelial barrier during inflammation; however, whether ilLC2 cells produce amphiregulin to mediate tissue repair is yet to be determined. ${ }^{41}$

The principal transcriptional factors implicated in the differentiation and development of ILC2s are GATA3 and retinoic acid-related orphan receptor alpha $(\mathrm{ROR} \alpha){ }^{44}$ Human ILC2s highly express GATA3 and are found to be enriched in nasal polyps of patients with chronic rhinosinusitis, a typical type 2-mediated disease. Nasal polyp epithelial cells express thymic stromal lymphopoietin (TSLP), which promotes activation of signal transducer and activator of transcription 5 (STAT5) and GATA3 expression. ${ }^{45}$ 


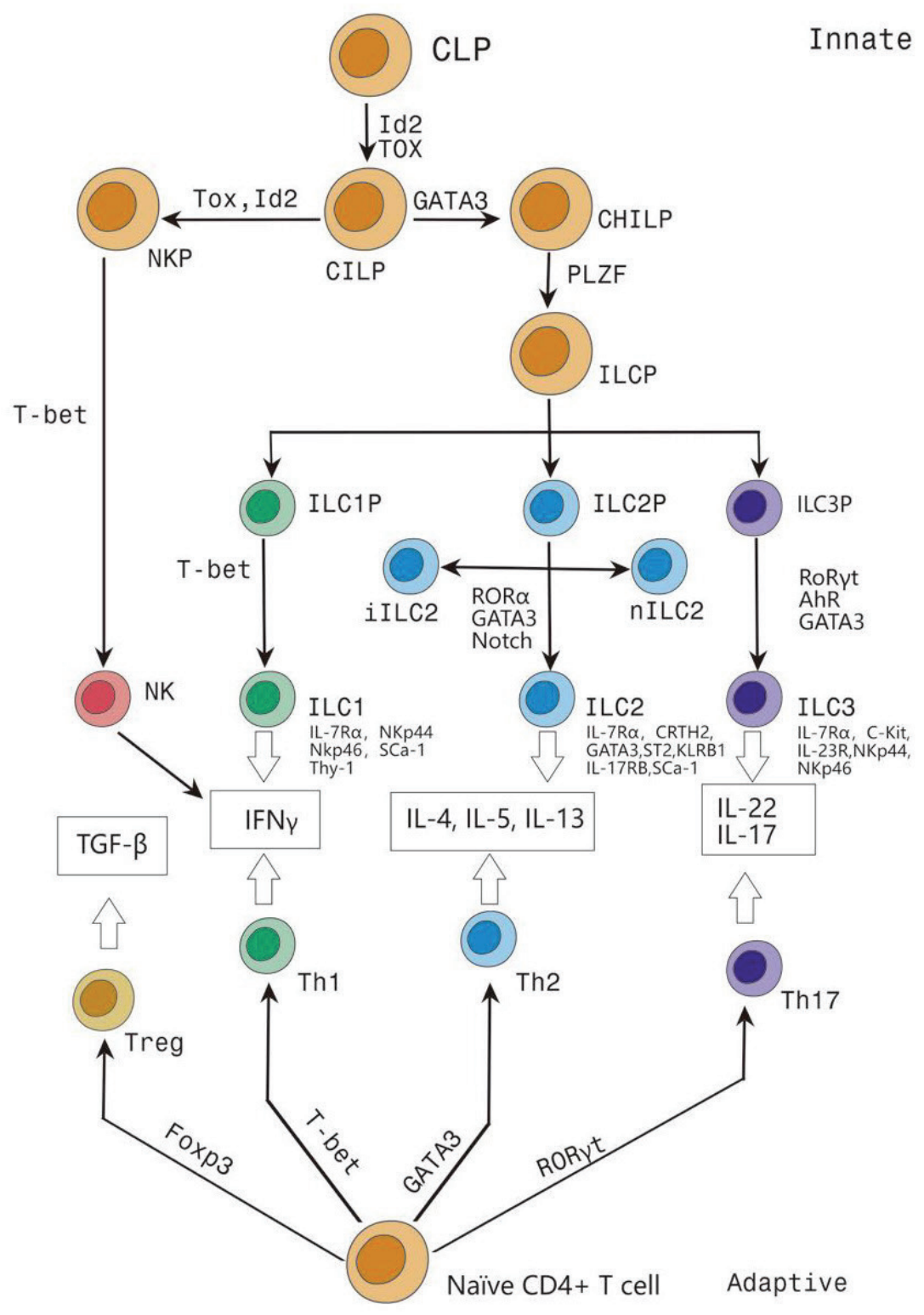

Figure 1 ILC family exhibit resemblance to TH2 cells in cytokine production and transcription factors. Shows ILC2 development and transcription factors. CLP: common lymphoid progenitor; CILP: common IL-R $\square+$ innate lymphoid progenitors; NKP: natural killer cell progenitor; CHILP: common helper innate lymphoid progenitors; ILCP: innate lymphoid cell progenitor; GATA3: GATA binding protein 3; ROR $\alpha$ : retinoic acid receptor-related orphan receptor alpha.

Deletion of GATA3 in all hematopoietic lineages at a very early stage of development abolish all helper-like ILCs. ILC2s depend on GATA3 for their development, and low levels of GATA3 are also required for the development of ILC3 subset (NKp46+); however, deletion of GATA3 later in the development results in the impaired differentiation of ILC2 cells, but not ILC3 cells, which shows that GATA3 is critical for the development and maintenance of ILC2s but not other ILCs. ${ }^{46}$ The intracellular adhesion molecule-1 (ICAM-1) is also required for the development of ILC2s, where ICAM 1- and ILC2s show impaired extracellular signaling-regulated kinase (ERK) pathway, which leads to diminished expression of GATA3 and production of type 2 cytokines. ${ }^{47}$ ROR $\alpha$ is identified as a regulator of ILC2 differentiation and function and this transcription factor is essential for the development of ILC2. ${ }^{48}$ ROR $\alpha$ is highly expressed in the growth of ILC2 cells, but not other ILC subsets. ${ }^{41}$ Another role of ROR $\alpha$ is in directing ILC2 proliferation and effector function.

ILC2-like cells were detected in peripheral tissues of ROR $\alpha$-deficient mice; these cells fail to expand in response to stimulating cytokines. ${ }^{48}$ Hence, GATA3 and ROR $\alpha$ are essential for the development, maintenance, and functioning of ILC2s. ${ }^{49}$ Similarly, transcription factor 1 (TCF-1) and notch signaling also play a role in the development of ILC2, as notch signaling induces TCF-1. TCF-1 is a critical transcription factor required for the expression of GATA3 
and ROR $\alpha$ (two important transcription factors known to be vital for the development of ILC2); it also appears to be an important factor for the expression of IL-33R by ILC2. A loss of TCF-1 expression impairs the ability of ILC2 to produce type 2 effector cytokines (IL-5 and IL-13). ${ }^{50}$ TGFbeta (TGF $\beta$ ) exhibits a cell-intrinsic role in programming the development of ILC2 by upregulation of ST2 expression in their progenitors (CHILP and ILC2P) mediated partially via MEK1/2-dependent but Smad3- and TAK1-independent pathways. TGF $\beta$ simultaneously plays an important role in the functioning, homeostasis, and maintenance of ILC2. It is reported that deficiency in TGF $\beta$ signaling results in the unsuccessful development of ILC2 and a significant decline in total numbers of ILC2s. ${ }^{51}$ IL-33 and IL-25 signaling might also play a role in the development of ILC2. ${ }^{41}$ In addition, E3 ubiquitin ligase Von Hippel-Lindau VAL, a new molecule identified recently, plays a significant role in promoting maturation and development of ILC2s. It was reported that a deletion of E3 ubiquitin ligase VHL in innate lymphoid progenitors minimally affected early-stage bone ILC2s but caused a selective and intrinsic decrease in mature ILC2 numbers in peripheral non-lymphoid tissues, resulting in reduced type 2 immune responses. ${ }^{52}$ Proliferation and survival of ILC2 cells, the cytokine-independent function of ILC2 cells, could directly regulate $T$ cell activation, and ILC2 expression of MHC class II could present antigen to T cells, triggering $\mathrm{T}$ cell-derived IL-2 production. As a result, such IL-2 would promote ILC2 proliferation. ${ }^{53}$ IL-9 signaling is crucial for the survival of activated ILC2s, as shown in a study, where IL-9 receptor (IL-9R)-deficient mice displayed reduced numbers of ILC2 $s$ in the lung after infection, resulting in impaired IL-5, IL-13, and amphiregulin levels. ${ }^{54}$ Another cytokine, IL-7, promotes ILC2 proliferation and survival. ${ }^{55}$

\section{ILC2 in Inflammation}

ILC2s belong to one of the three subsets of ILC populations arising from common lymphoid progenitors. ${ }^{56}$ Among ILC subsets, ILC2s are the prominent cells in the lung tissue, and upon ILC2 activation, they produce large amounts of type 2 cytokines (IL-5, IL-13, IL-9, and IL-4). ${ }^{57}$ ILC2s influence both adaptive and innate immunity and are regarded as the counterpart of the Th2 immune pathway. ${ }^{58}$ ILC2 cells are essential drivers of inflammation; ${ }^{59}$ they are the spotlight of type 2 immune response ${ }^{60}$ and have been a source of inflammation in many clinical diseases, ${ }^{61}$ such as in inflammatory bowel disease (IBD), ${ }^{62}$ intestinal helminths infection, ${ }^{63}$ and allergic rhinitis. ${ }^{64}$

In the context of asthma inflammation, ILC2 cells line the mucosal surface of the airway to protect host from adversity of pathogenic microbes, allergens, and pollutants. ${ }^{65}$ Pathogenic recognition, allergen exposure, or damage to the barrier function of the airway epithelium enhances mucosal permeability of foreign substances into the airway epithelium of the patients with asthma; ${ }^{66}$ these initiate the release of epithelial cell-derived cytokines, such as TSLP, IL-25, and IL-33, hence ILC2s alarmins. ${ }^{67}$ They activate ILC2s in an antigen-independent manner via their respective receptors TSLPR, IL-17RB, and ST2. ${ }^{68}$ Overexpression of TSLP in the lungs leads to the development of AHR. ${ }^{69}$ Likewise, TSLPR-deficient mice reported having impaired type 2 responses. ${ }^{70} \mathrm{IL}-25$ is expressed in the epithelial lung cells following allergen exposure. In airway epithelial cells, transgenic overexpression of IL-25, and intraperitoneal or intranasal administration of IL-25, promotes type 2 responses. Correspondingly, IL-25-deficient mice reported having decreased AHR in a model of asthma. ${ }^{71}$

IL-33, or IL-2/33, is a potent activator of ILC2, resulting in enhanced production of critical effector cytokines IL-5 and $\mathrm{IL}-13$, which are responsible for the development of allergic airway inflammation. ${ }^{72,73}$ On the other hand, IL-33-deficient mice have impaired AHR, and mice deficient in IL-33 receptor, ST2 mice have declined parasitic expulsion. ${ }^{69}$ On the contrary, other cytokines have shown to inhibit mouse and human ILC2 responses, such as IFN-beta, IL-10, TGF-beta, IFNgamma, and IL-27. ${ }^{74}$ In response to epithelial cell-derived cytokines, ILC2s produce a significant amount of type 2 cytokines (IL-5, IL-13, and IL-4) (Figure 2). ${ }^{44,75,76}$ IL-5 functions in eosinophil proliferation, differentiation, maturation, migration to tissue sites and survival, as well as in the prevention of eosinophil apoptosis; eosinophils are vital players in the pathogenesis and severity of asthma. ${ }^{77} \mathrm{IL}-13$ acts on the airway smooth muscle cells, inducing AHR, promoting differentiation of goblet cells, and contributing to hypersecretion of the mucus. ${ }^{78}$ ILC2s have been found to be an important source of IL-9 after the administration of papain..$^{58}$ IL-9 promotes mast cell hyperplasia, ${ }^{79} \mathrm{AHR}$, and mucus overproduction. ${ }^{80}$ Moreover, IL-9+ILC2s have been shown to promote resolution of lung inflammation by impairing caspase-1 activation, which prevents lung endothelial cells from pyroptosis, and particularly treatment with rlL-9 recombinant protein promotes ILC2-dependent Treg activation and successfully resolves inflammation. ${ }^{81-83}$ Subsequently, IL-4 induces IgE isotype switching in B cells and promotes eosinophil transmigration across endothelium. ${ }^{84}$

\section{ILC2 provokes inflammation in asthma}

ILC2-associated asthma is frequently associated with higher eosinophil counts. Eosinophilia is a predictor of the severity of asthma and possible exacerbations; it also predicts the outcome of asthma care with ICS. ${ }^{85}$ Late-onset asthma that develops in adulthood is often associated with chronic rhinosinusitis and nasal polyps; thus, increased numbers of ILC2s have been detected in these nasal polyps, resulting in severe eosinophilia and persists despite inhaled corticosteroid treatment. ${ }^{86}$ Besides, Nagakumar et al. ${ }^{87}$ surveyed children with severe therapy-resistant asthma (STRA), children with difficult asthma (DA), and a control group where sputum ILC2s were significantly higher in STRA patients compared to DA and disease controls; but ILC2s decreased in vivo post-intramuscular triamcinolone. Liu et al. ${ }^{88}$ reported persistent steroid resistance in ILC2-associated asthma in asthmatic patients with increased TSLP levels in an MEKand STAT5-dependent manner. However, this effect was reversed by MEK and STAT5 inhibitors. Likewise, Verma et al. ${ }^{89}$ demonstrated, using ST2 knockout (KO) mice, deletion of ST2, subsequently leading to increased production of TSLP, hence the increased number of ILC2s; this resulted in increased airway inflammation and persistence 


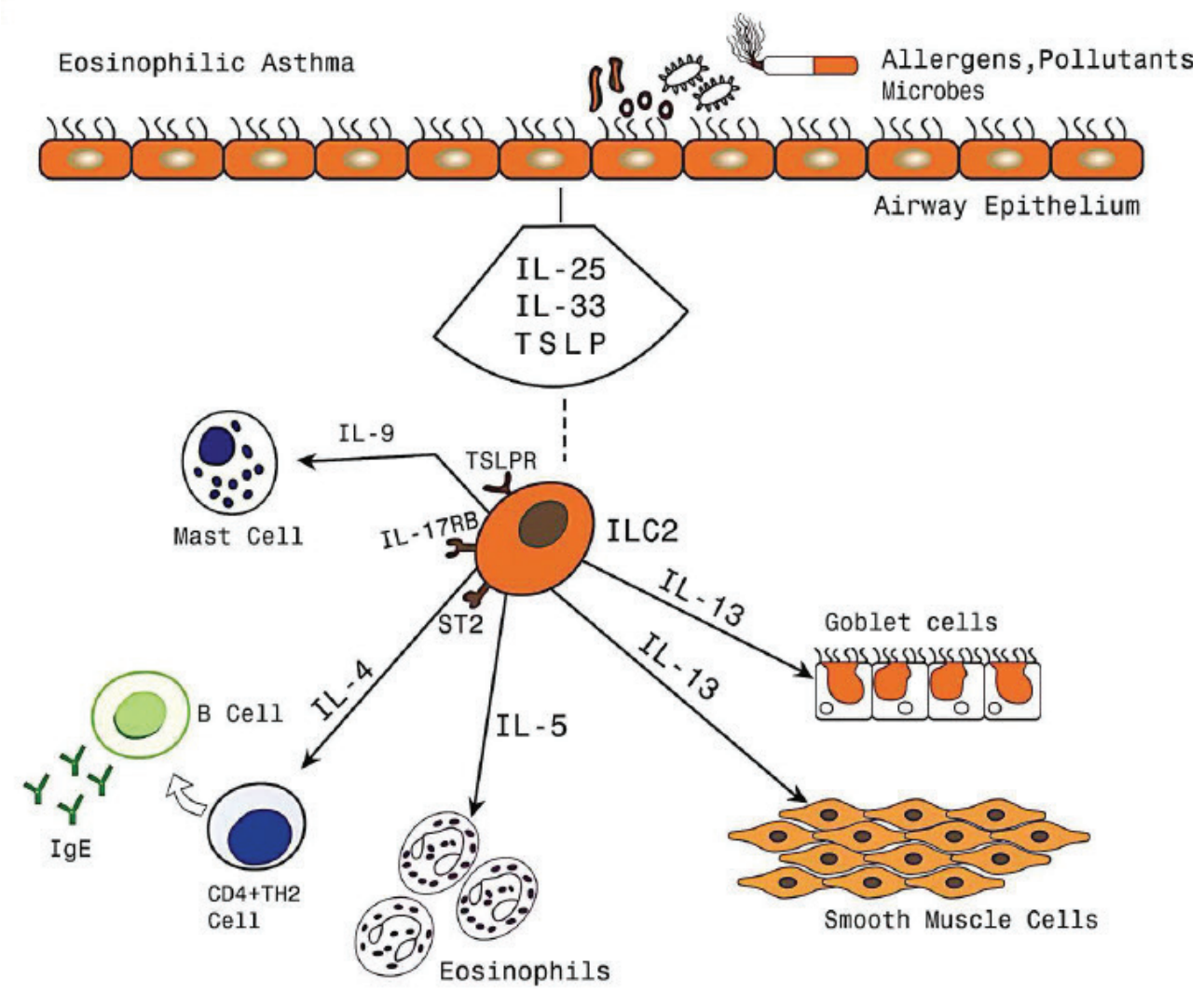

Figure 2 Damage to the epithelium induced the release of epithelial-derived cytokines (IL-25, IL-33, and TSLP) which activate ILC2s via their receptors (IL-17RB, ST2, and TSLRP, respectively). Activated ILC2s produce significant amount of type 2 cytokines (IL-4, IL-5, and IL-13), resulting in airway eosinophilia, mucus hypersecretion, and airway hyperreactivity. TSLP: thymic stromal lymphopoietin.

of asthma symptoms. Human ILC2s co-culture with bronchial epithelial cells, ILC2s (via IL13) impaired the epithelial barrier by disrupting epithelial tight junction (TJ), rendering barrier leakiness, hence the asthma pathogenesis..$^{90}$ Smith et al., ${ }^{17}$ in their research, analyzed blood and sputum ILC2s and intracellular IL-5 and IL-13 in patients with severe asthma, since ILC2s are the predominant source of IL-5 and IL-13. Sputum IL-5(+) IL-13(+) ILC2s are significantly higher in patients with severe asthma compared to mild asthma and the control group, resulting in persistent airway eosinophilia, with sputum eosinophils $>3 \%$, despite high-dose eosinophilia. Similarly, in children with severe asthma, the number of ILC2s was more abundant in bronchial mucosa and broncho alveolar lavage (BAL) compared to non-asthmatic children, and ILC2s were correlated with bronchial mucosa eosinophilia and persistent symptoms. ${ }^{91}$ Moreover, Jia et al. ${ }^{92}$ reported a significant increase in ILC2s in asthma subjects relative to healthy groups and a significantly higher percentage of IL-13+ILC2s in circulating blood of patients in the uncontrolled group compared to a well-controlled group and stable control subjects. They further noted that IL-13+ILC2s isolated from peripheral blood mononuclear cells (PBMCs) were more resistant to glucocorticoid than Th2 cells in human asthma. Additionally, Lee et al. ${ }^{93}$ investigated 28 asthmatics (12 non-severe and 16 severe) with chronic rhinosinusitis. They found that severe asthmatics had a higher expression of ILC2 cell counts,
TSLP, IL-25, IL-33, and Th2-driven cytokines (IL-4, IL-5, IL-9, and IL-13) in their nasal tissue.

\section{ILC2 mediates airway remodeling in asthma}

Airway remodeling is an alteration in the size, mass, or number of tissue structural components that occurs in response to injury and inflammation, resulting from repeated tissue injury. ${ }^{94}$ ILC2 is vital for maintaining tissue repair and contributes to chronic pathology such as airway fibrosis resulting in scars of lung tissue and airway narrowing. ${ }^{95,96}$ ILC2 activation promotes tissue remodeling induced through the expansion of ILC2 effector cytokine influence as airways vascularization, airways fibrosis, and airways smooth muscle hypertrophy. ${ }^{97}$ Remarkably, ILC2-derived cytokines (IL-5, IL-9, and IL13) in a murine model have shown to contribute to airway remodeling in asthma. ILC2-derived IL-13 alongwith IL-9 promotes subepithelial fibrosis, AHR, smooth muscle increase, and epithelial mucus production. ILC2derived IL- 5 brings about the proliferation of eosinophils that express the pro-fibrotic growth factor TGF $\beta .{ }^{98}$ TGF $\beta(+)$ eosinophils activate the Smad-2/3 signaling pathway which contributes to airway remodeling observed in increased levels of collagen deposition and increased numbers of angiogenic blood vessels. A study done in human asthma reported that a single dose of antilL- 5 significantly reduced 
the levels of TGF $\beta(+)$ eosinophils, resulting in low levels of remodeling observed in reduced deposition of extracellular matrix-associated remodeling proteins procollagen and tenascin. ${ }^{99}$ Additionally, the nILC2 cell population produces significant amounts of amphiregulin, ${ }^{41}$ a molecule of epidermal growth factor family linked to regulating tissue remodeling and repair during acute epithelial injury and asthma. ${ }^{100}$

In the airway remodeling setting, ILC2 produced amphiregulin upon IL-33 stimulation. Amphiregulin expression was elevated in the lung following exposure to the H1N1 subtype of influenza A virus, which resulted in significant damage to the respiratory epithelium. In addition to tissue remodeling, ILC2 promotes a favorable role in tissue repair response in the lung following acute epithelial damage. Treatment with recombinant amphiregulin, butnotIL-13, effectively restored lung function and epithelial repairin ILC-depleted influenza virus-infected mice, proposing that ILC2-derived amphiregulin is crucial in promoting airway epithelial repair. ${ }^{101}$ Also, ILC2-derived IL-9 promotes tissue repair, whereby IL-9 improved emphysema-like tissue damage after chronic helminth-induced lung injury. ${ }^{54}$ Furthermore, CD25+CD90+ST2+ILC2 cells accumulated in the lung after H1N1 infection and depletion of ILC2s in influenza virus-infected Rag1KO hosts using an anti-CD90 monoclonal antibody treatment resulted in critically declined lung function, compromised lung epithelial barrier integrity, and increased host mortality, indicating that lung ILC2s are key modulators of lung tissue remodeling and epithelial repai. ${ }^{101}$ Meanwhile, just as the role of conventional $C D 4+T$ cells in the airway remodeling has remained unclear, ${ }^{102}$ so does the role of ILC2. ${ }^{98}$ This requires further investigation to provide us with a clear understanding of the immune and inflammatory cell pathways involved in the progression of $\mathrm{AHR}$, and probably provide key insight into biomarkers or genotypes to indicate the severity of $\mathrm{AHR}$, as well as to serve as a therapeutic target to prevent or reverse airways' pathological changes in asthma. ${ }^{99}$

\section{Conclusion}

ILC2s are in the spotlight in asthma pathogenesis, as ILC2s have been on the radar of many scientific studies in recent years. ILC2s studies have shown more evidence on the potential therapeutic approach in the management of type 2 airway diseases such as asthma. Moreover, full and vivid understanding that surrounds the ILC2 inflammation process will aid in therapeutic advancement, as some have already been developed and are quite useful in the treatment of asthma, while others are still working and progress is far from proven. Additionally, ILC2s in asthma could aid asthma phenotyping to establish an accurate diagnosis and provide appropriate treatment strategy. Lastly, the relationship between ILC2 and its counterpart (Th2 cells) in asthma is an intriguing area that requires further investigations.

\section{Acknowledgments}

This review was supported by the pediatric department of the affiliated hospital of Jiangsu University.

\section{References}

1. GBD 2015 Chronic Respiratory Disease Collaborators. Global, regional, and national deaths, prevalence, disability-adjusted life years, and years lived with disability for chronic obstructive pulmonary disease and asthma, 1990-2015: A Systemic analysis for the Global Burden of Disease Study 2015. GBD 2015 chronic Respiratory Disease Collaborators. Lancet Respir Med. 2017 Sep;5(9):691-706.

2. Ferrante G, Antona R, Malizia V, Montalbano L, Corsello G, La Grutta S, et al. Smoke exposure as a risk factor for asthma in childhood: A review of current evidence. Allergy Asthma Proc. 2014.35.3789. https://doi.org/10.2500/aap.2014.35.3789

3. Asher I, Pearce N. Global burden of asthma among children. Int J Tuberc Lung Dis. 2014 Nov;18(11):126-78. https://doi. org/10.5588/ijtld. 14.0170

4. Giuliana Ferrante, Stefania La Grutta, et al. Front Pediatr. 2018;6:186. https://doi.org/10.3389/fped.2018.00186

5. Sporik R, Holgate ST, Plat-Mills TAE, Cogswell JJ. Exposure to house-dust mite allergens (Der p1) and the development of asthma in childhood: A prospective study. $\mathrm{N}$ Engl J Med. 1990;323:502-7. https://doi.org/10.1056/NEJM19900 8233230802

6. Rosenstreich DL, Eggleston P, Kattan M, Baker D, et al. The role of cockroach allergy and exposure to cockroach allergen in causing morbidity among inner-city children with asthma. N Engl J Med. 1997;336:1356-63. https://doi.org/10.1056/NEJM19 9705083361904

7. Arruda LK, Chapman MD. The role of cockroach in asthma. Curr Opinion Pulmon Med. 2001 Jan;7(1):14-9. https://doi. org/10.1097/00063198-200101000-00003

8. Arruda LK, Vailes LD, Ferriani VP, et al. Cockroach allergens and asthma. J Allergy Clin Immunol. 2001 Mar;107(3):419-28. https://doi.org/10.1067/mai.2001.112854

9. Sporik R, Squillace SP, Ingram JM, et al. Mite, cat, and cockroach exposure allergen sensitization, and asthma in children: A case-control study of three schools. Thorax. 1999 Aug;54(8):675-80. https://doi.org/10.1136/thx.54.8.675

10. Leader BP, Belanger K, Triche E, Holford T, Gold DK, Kim Y, et al. Dust mite, cockroach, cat and dog allergen concentrations in homes in homes of asthmatic children in the northeast United States: Impact of socioeconomic factors and population density. Environ Health Perspect. 2002 Apr;110(4):419-25. https://doi.org/10.1289/ehp.02110419

11. Halonen M, Stern DA, Wright AL, Taussig LM, Martinez FD. Alternaria as a major allergen for asthma in children raised in a desert environment. Am J Respir Crit Care Med. 1997 Apr;155(4):1356-61. https://doi.org/10.1164/ajrccm. 155.4.9105079

12. Halonen M, Stern DA, Lohman C, et al. Two subphenotypes of childhood asthma that differs in maternal and paternal influences on asthma risk. Am J Respir Crit Care Med. 1999 Aug;160(2):546-70. https://doi.org/10.1164/ajrccm. 160.2.9809038

13. Hekking PP, Bel EH. Developing and emerging clinical phenotypes. J Allergy Clin Immunol Pract. 2014 Nov-Dec;2(6):67180; quiz 681. https://doi.org/10.1016/j.jaip.2014.09.007

14. Hara K, Lijima k, Elias Mk, Seno S, Tojima I, et al. Airway uric acid is a sensor of inhaled protease allergens and initiates type 2 immune responses in the respiratory mucosa. J Immunol. 2014 May 1;192(9):4032-42. 10.4049/jimmunol.1400110

15. Salter BM, Aw M, Sehmi R. The role of type 2 innate lymphoid cells in eosinophilic asthma. J Leukoc Biol. 2019;106(4):889901. https://doi.org/10.1002/JLB.3MR1217-497R

16. Woodruff PG, Modrek B, Choy DF, et al. T-helper 2-driven inflammation defines major subphenotypes of asthma. Am J Respir Crit Care Med. 2009 Sep 1;180(5):388-95. https://doi. org/10.1164/rccm.200903-03920C 
17. Smith SG, Chen R, Kjarsgaard M, Oliveria JP, et al. Increase number of activated group 2 innate lymphoid cells in the airway of patients with severe asthma and persistent airway eosinophilia. J Allergy Clin Immunol. 2016 Jan;137(1):75-86.e8. https://doi.org/10.1016/j.jaci.2015.05.037

18. Kindermann $M$, et al. ILC2s in infectious diseases and organ-specific fibrosis. Semin Immunopathol. 2018 Jul; 40(4):379-392. https://doi.org/10.1007/s00281-018-0677-x

19. Bush A. Pathophysiological mechanism of asthma. Front Pediatr. 2019;7:68. https://doi.org/10.3389/fped.2019.00068

20. Lloyd Clare M, Hessel EM. Function of T cells in asthma: More than just TH2 cells. Nat Rev Immunol. 2010 Dec;10(12):10. https://doi.org/10.1038/nri2870

21. Moqbel R, et al. Allergy, asthma, and inflammation: Which inflammatory cell type is more important? Allergy Asthma Clin Immunol. 2008;4(4):150-156. https://doi. org/10.1186/1710-1492-4-4-150

22. Han Gao, et al. Pathological roles of neutrophil-mediated inflammation in asthma and its potential for therapy as a target. J. Immunol Res. 2017;2017:3743048. https://doi. org /10.1155/2017/3743048

23. Bousquet $\mathrm{J}$, et al. Eosinophilic inflammation in asthma. $\mathrm{N}$ Engl J Med. 1990 Oct 11;323(15):1033-9. https://doi.org/10.1056/ NEJM199010113231505

24. Wang $Y$, et al. Role of airway epithelial cells in the development of asthma and allergic rhinitis. Respir Med. 2008 Jul;102(7):949-55. https://doi.org/10.1016/j.rmed.2008.01.017

25. Balhara J, Gounni AS. The alveolar macrophages in asthma: A double-edge sword. Mucosal Immunol. 2012 Nov;5(6):605-9. https://doi.org/10.1038/mi.2012.74

26. Kim JH, et al. Role of natural killer cells in airway inflammation. Allergy Asthma Immunol Res. 2018 Sep;10(5):448-56. https://doi.org/10.4168/aair.2018.10.5.448

27. Bernink JH, et al. The role of ILC2s in pathology of type 2 inflammatory diseases. Curr Opin Immunol. 2014 Dec;31:11520. https://doi.org/10.1016/j.coi.2014.10.007

28. Inflammation and host response to injury a multi-disciplinary research program. Blue Grant; 2001.

29. Rackemann FM. A working classification of asthma. Am J Med. 1947;3:601-6. https://doi.org/10.1016/0002-9343(47)90204-0

30. Evans CK, et al. Mucus hypersecretion in asthma: Causes and effects. Curr Opin Pulm Med. 2009 Jan;15(1):4-11. https://doi org/10.1097/MCP.0b013e32831da8d3

31. Hirota N, Martin JG. Mechanisms of airway remodeling. Chest. 2013 Sep;144(3):1026-32. DOI: 10.1378/chest.12-3073

32. Georas SN, Rezaee F. Epithelial barrier function: At the frontline of asthma immunology and allergic airway inflammation. J Allergy Clin Immunol. 2014 Sep;134(3):509-20. https://doi. org/10.1016/j.jaci.2014.05.049

33. Vignola $A M$, et al. New evidence of inflammation in asthma. Thorax. 2000 Oct;55 Suppl 2;S52-S60. https://doi.org/10.1136/ thorax.55.suppl 2.559

34. Liu C, Zhang X, et al. Role of epithelial chemokines in the pathogenesis of airway inflammation in asthma (review). Mol Med Rep. 2018 May;17(5):6935-41. https://doi.org/10.3892/ mmr.2018.8739

35. Ishmael FT. The inflammatory response in the pathogenesis of asthma. J Am Osteopath Assoc. 2011 Nov;111(11, Supp (7):S117. PMID: 22162373

36. Salimi M, Ogg G. Innate lymphoid cells and the skin. BMC Dermatol. 2014 Nov 26;14:18. https://doi.org/10.1186/ 1471-5945-14-18

37. Walker JA, et al. Innate lymphoid cells - How did we miss them? Nat RevImmunol.2013 Feb;13(2):75-87. https://doi.org/10.1038/ nri3349

38. Spits $\mathrm{H}$, et al. Innate lymphoid cells - A proposal for uniform nomenclature. Nat Rev Immunol. 2013 Feb;13(2):145-9. https://doi.org/10.1038/nri3365
39. Tait Wojno ED, Beamer CA. Isolation and identification of innate lymphoid cells (ILCS) for immunotoxicity testing. Methods Mol Biol. 2018;1803:353-70. https://doi. org/10.1007/978-1-4939-8549-4_21

40. Halim TY. Group 2 innate lymphoid cells in disease. Int Immunol. 2016 Jan;28(1):13-22. https://doi.org/10.1093/intimm/ dxv050

41. Huang $Y$, Paul WE. Inflammatory group 2 innate lymphoid cells. Int Immunol. 2016 Jan;28(1):23-28. https://doi.org/10.1093/ intimm/dxv044

42. Spooner CJ, Lesch J, et al. Specification of type 2 innate lymphocytes by the transcriptional determinant Gfi1. Nat Immunol. 2013 Dec;14(12):1229-36. https://doi.org/10.1038/ni.2743

43. Tian J, et al. Methionine enkephalin inhibits influenza A virus infection through upregulating antiviral state in RAW264.7 cells. Int Immunopharmacol. 2020 Jan;78:106032. https://doi. org/10.1016/j.intimp.2019.106032

44. Xiong $\mathrm{J}$, et al. Functions of Group 2 innate lymphoid cells in the tumor microenvironment. Front Immunol. 2019;10:1615. https://doi.org/10.3389/fimmu.2019.01615

45. Mjosberg J, et al. The transcription factor GATA3 is essential for the function of human type 2 lymphoid cells. Immunity. 2012 Oct 19;37(4):649-59. https://doi.org/10.1016/j. immuni.2012.08.015

46. Hoyler T, et al. The transcription factor GATA3 controls cell fate and maintenance of type innate lymphoid cells. Immunity. 2012 Oct 19;37(4):634-48. https://doi.org/10.1016/j. immuni.2012.06.020

47. Lei $\mathrm{AH}$, Xiao Q, et al. ICAM-1 controls development and function of ILC2. J Exp Med. 2018 Aug 6;215(8):2157-74. 10.1084/ jem.20172359

48. Wong $\mathrm{SH}$, et al. Transcription factor RORalpha is critical for nuocyte development. Nat Immunol. 2012;13:229-36. https:// doi.org/10.1038/ni.2208

49. Walker JA, et al. Development and function of group 2 innate lymphoid cells. Curr Opin Immunol. 2013 Apr;25(2):148-55. https://doi.org/10.1016/j.coi.2013.02.010

50. Mielke LA, et al. TCF-1 controls ILC2 and NKp46+ ROR gammat+ innate lymphocyte differentiation and protection in intestinal inflammation. J Immunol. 2013 Oct 15;191(8):438391. https:// doi.org/10.4049/jimmunol.1301228

51. Wang $L$, et al. TGF-beta induces ST2 and programs ILC2 development. Nat Commun. 2020 Jan 7;11(1):35.

52. Li Q, Li D, Zhang X, et al. E3 ligase VHL promotes Group 2 innate lymphoid cell maturation and function via glycolysis intubation and induction of interleukin-33 receptor. Immunity. 2018 Feb 20;48(2):258-270.e5. doi: 10.1016/j. immuni.2017.12.013. Epub 2018 Feb 13.

53. Drake LY, lijima K, Kita H. Group 2 innate lymphoid cells and CD4+ $T$ cells cooperate to mediate type 2 immune response in mice. Allergy. 2014 Oct; 69(10):1300-7. https://doi.org/10.1111/ all.12446

54. Turner J-E, et al. IL-9-mediated survival of type 2 innate lymphoid cells promote damage control in helminth-induced lung inflammation. J Exp Med. 2013 Dec 16;210(13):2951-65. https://doi.org/10.1084/jem.20130071

55. Elia D. Tait Wojno. Innate lymphoid cells: An emerging population in type 2 inflammation. Cell Host Microbe. 2012 Oct 18; 12(4):445-457. doi: 10.1016/j.chom.2012.10.003

56. Pishdadian A, et al. Type 2 innate lymphoid cells: Friends or foes role in airway allergic inflammation and asthma. J Allergy (Cairo). 2012;2012:130937. https://doi.org/10.1155/2012/130937

57. Lai DM, Shu Q, Fan J. The origin and role of innate lymphoid cells in the lung. Mil Med Res. 2016 Aug 19;3:25. https://doi. org/10.1186/s40779-016-0093-2

58. Gasteiger G, Rudensky AY. Interactions between innate and adaptive lymphocytes. Nat Rev Immunol. 2014 Sep;14(9):1319. https://doi.org/10.1038/nri3726 
59. Karagiannis F, Wilhelm C. More is less: IL-9 in the resolution of inflammation. Immunity. 2017 Sep 19;47(3):403-405.

60. Helfrich S, et al. Group 2 innate lymphoid cells in respiratory allergic inflammation. Front Immunol. 2019 Jun 7;10:930. https://doi.org/10.3389/fimmu.2019.00930

61. Kato A. Group innate lymphoid cells in airway disease. Chest. 2019 Jul;156(1):141-9. https://doi.org/10.1016/j. chest.2019.04.101

62. Geremia A, et al. Innate lymphoid cells in intestinal inflammation. Front Immunol. 2017 Oct 13;8:1296. https://doi. org/10.3389/fimmu.2017.01296

63. Loser S, Smith KA, et al. Innate lymphoid cells in Helminths infections - Obligatory or accessory? Front Immunol. 2019 Apr 10;10:620. https://doi.org/10.3389/fimmu.2019.00620

64. Fan D, et al. Allergen-dependent differences in ILC2s frequencies in patients with allergic rhinitis. Allergic Asthma Immunol Res. 2016 May;8(3):216-222. https://doi.org/10.4168/ aair.2016.8.3.216

65. Lambrecht BN, Hammad H. Allergens and the airway epithelium response. J Allergy Clin Immunol. 2014 Sep;134(3):499507. https://doi.org/10.1016/j.jaci.2014.06.036

66. Gon Y, Hashimoto S. Role of airway epithelial barrier dysfunction in the pathogenesis of asthma. Allergol Int. 2018 Jan;67(1):12-17. https://doi.org/10.1016/j.alit.2017.08.011

67. Karta MR, Broide DH, Doherty TA. Insight into Group 2 innate lymphoid cells in human airway disease. Curr Allergy Asthma Rep. 2016 Jan;16(1):8. Curr Allergy Asthma Rep. 2016 Jan;16(1):8. doi: 10.1007/s11882-015-0581-6.

68. Brusselle GG, et al. Eosinophils in the spotlight: Eosinophilic airway inflammation in non-allergic asthma. Nat Med. 2013 Aug;19(8):977-9. https://doi.org/10.1038/nm.3300

69. Lincona-Limon P, Kim LK, Palm NW, et al. TH2, allergy and group 2 innate lymphoid cells. Nat Immunol. 2013 Jun;14(6):536-42. Nat Immunol. 2013 Jun;14(6):536-42. doi: 10.1038/ni.2617.

70. He, R, et al. TSLP acts on infiltrating effector T cells to derived allergic skin inflammation. Proc. Natl. Acod. Sci (USA). 2008;105:11875-80. https://doi.org/10.1073/pnas.0801532105

71. Chiba $Y$, et al. Interleukin-13 augments bronchial smooth muscle contractility with an upregulation of Rho A protein. Am J Respir Cell Mol Biol. 2009 Feb;40(2):15967. https://doi. org/10.1165/rcmb.2008-01620C

72. $\mathrm{Xu} \mathrm{H}$, et al. Interleukin-33 contributes to ILC2 activation and early inflammation-associated lung injury during abdominal sepsis. Immunol Cell Biol. 2018 Oct;96(9):935-47. https://doi. org/10.1111/imcb.12159

73. Matsushita K, et al. Regnase-1 degradation is crucial for IL-33and IL-25-mediated ILC2 activation. JCI Insight. 2020 Feb 27;5(4).pii:e131480. https://doi.org/10.1172/jci.insight.131480

74. Doherty TA, Broide DH. Pathways to limit Group 2 innate lymphoid cell activation. J Allergy Clin Immunol. 2017 May;139(5):1465-67. https://doi.org/10.1016/j.jaci.2016.12.003

75. Kubo M. Innate and adaptive type immunity in lung allergic inflammation. Immunol Rev. 2017 Jul;278(1):162-72. doi: 10.1111/imr.12557

76. Bouchery $\mathrm{T}$, et al. ILC2s-trailblazers in the host response against intestinal helminths. Front Immunol. $2019 \mathrm{Apr}$ 4;10:623. doi: 10.3389/fimmu.2019.00623

77. Garcia G, et al. Anti-interleukin-5 therapy in severe asthma. Eur Respir Rev. 2013 Sep1;22(129):251-7. https://doi.org/10.1183/ 09059180.00004013

78. Real EL, Lockey RF. Interleukin-13 signaling and its role in asthma. World Allergy Organ J. 2011 Mar;4(3):54-64. https:// doi.org/10.1097/WOX.0b013e31821188e0

79. Martinez-Gonzalez I, et al. Lung ILC2s link innate and adaptive responses in allergic inflammation. Trends Immunol. 2013 Mar;36(3):189-95. https://doi.org/10.1016/j.it.2015.01.005
80. Hauber H-P, Hamid Q. The role of interleukin-9 in asthma. Allergol Int 2005;54:71-78. https://doi.org/10.2332/ allergolint.54.71

81. Karagiannis F, et al. More is less: IL-9 in the resolution of inflammation. Immunity. 2017 Sep19;47(3):403-5. https://doi. org/10.1016/j.immuni.2017.09.004

82. Starkey MR, et al. Pulmonary group 2 innate lymphoid cells: Surprises and changes. Mucosal Immunol. 2019 Mar;12(2):299311. https://doi.org/10.1038/s41385-018-0130-4

83. Rauber $\mathrm{S}$, et al. Resolution of inflammation by interleukin-9-producing type 2 innate lymphoid cells. Nat Med. 2017 Aug;23(8):938-44. DOI: 10.1038/nm.4373

84. Steinke JW, Borish L. Th 2 cytokines and asthma-interleukin-4: Its role in the pathogenesis of asthma, and targeting it for asthma treatment with interleukin-4 receptor antagonists. Respir Res. 2001;2(2):66-70. https://doi.org/10.1186/rr40

85. Kostikas $\mathrm{K}$, et al. Blood eosinophils as biomarkers to drive treatment choices in asthma and COPD. Curr Drug Targets. 2018;19(16):1882-1896. https://doi.org/10.2174/1389450119666 180212120012

86. Bakakos A, et al. Severe eosinophilic asthma. J Clin Med. 2019 Sep;8(9):1375. https://doi.org/10.3390/jcm8091375

87. Nagakumar P, Puttar F, et al. Pulmonary type 2 innate lymphoid cells in pediatric severe asthma: Phenotype and response to steroids. Eur Respir J. 2019 Aug 29;54(2). https:// doi.org/10.1183/13993003.01809-2018

88. Liu S, Verma M, et al. Steroid resistance of airway type 2 innate lymphoid cells from patients with severe asthma: The role of thymic stromal lymphopoietin. J Allergy Clin Immunol. 2018 Jan;141(1):257-68. https://doi.org/10.1016/j. jaci.2017.03.032

89. Verma M, Liu S, et al. Experimental asthma persist in IL-33 receptor knockout mice because of the emergence of thymic stromal lymphopoietin-driven IL-9+ and IL-13+ type 2 innate lymphoid cell-subpopulations. J Allergy Clin Immunol. 2018 Sep;142(3):793-803. https://doi.org/10.1016/j. jaci.2017.10.020

90. Sugita K, Steer CA, et al. Type 2 innate lymphoid cells disrupt bronchial epithelial barrier integrity by targeting tight junctions through IL-13 in asthmatic patients. J Allergy Clin Immunol. 2018 Jan;141(1):300-10. https://doi.org/10.1016/j. jaci.2017.02.038

91. Clinical Trials.gov. Type 2 innate lymphoid cells in severe pediatric asthma (CLASSE). Identifier: NCT03784781. Available at: https://clinicaltrials.gov/ct2/show/NCT03784781

92. Jia $Y$, Fang $X$, et al. IL-13+ type 2 innate lymphoid cells correlate with asthma control status and treatment response. Am J Respir Cell Mol Biol. 2016 Nov;55(5):675-863. https://doi. org/10.1165/rcmb.2016-00990C

93. Lee $\mathrm{TJ}, \mathrm{Fu} \mathrm{CH}$, et al. Impact of chronic rhinosinusitis on severe asthma patients. PLoS One. 2017 Feb 15;12(2):e0171047. https://doi.org/10.1371/journal.pone.0171047

94. Larsson K. Monitoring airway remodeling in asthma. Clin Respir J. 2010 May;4 (Suppl 1):35-40. https://doi. org/10.1111/j.1752-699X.2010.00195.x

95. Starkey MR, et al. Pulmonary group 2 innate lymphoid cells: Surprises and challenges. Mucosal Immunol. 2019 Mar;12(2):299-311. https://doi.org/10.1038/s41385-018-0130-4

96. McKenzie AN. Type 2 innate lymphoid cells in asthma and allergy. Ann Am Thorac Soc. 2014 Dec;11(Suppl 5):5263-70. doi: 10.1513/AnnalsATS.201403-097AW

97. Dahlgren $M W$, et al. All along the watch tower: Group 2 innate lymphoid cells in allergic responses. Curr Opin Immunol. 2018 Oct;54:13-19. https://doi.org/10.1016/j.coi.2018.05.008

98. Doherty TA, et al. Airway innate lymphoid cells in the induction and regulation of allergy. Allergol Int. 2019 Jan;68(1):916. https://doi.org/10.1007/s42411-019-0059-y 
99. Broide DH. Immunologic and inflammatory mechanisms that drive asthma progression to remodeling. J Allergy Clin Immunol. 2008 Mar, 121(3):560-70. https://doi.org/10.1016/j. jaci.2008.01.031

100.Cheng $\mathrm{H}$, et al. Guards at the gate physiological and pathological roles of tissue resident innate lymphoid cells in the lung. Protein Cell. 2017 Dec;8(12):932. https://doi.org/10.1007/ s13238-017-0399-1
101. Monticelli LA, et al. Innate lymphoid cells: Critical regulators of allergic inflammation and tissue repair in the lung. Curr Opin Immunol. 2012 Jun;24(3):284-289. https://doi. org $/ 10.1016 / j . c o i .2012 .03 .012$

102. Kristein F, et al. Role of IL-4 receptor alpha-positive CD4+ T cells in chronic airway hyper-responsiveness. J Allergen Clin Immunol. 2016 Jun;137(6):1852-62. https://doi.org/10.1016/j. jaci.2015.10.036 